\title{
Mating advantage of multiple male ornaments in the Barn Swallow Hirundo rustica gutturalis
}

\author{
Masaru HASEGAWA ${ }^{1, \#}$, Emi ARAI ${ }^{2}$, Mamoru WATANABE $^{1}$ and Masahiko NAKAMURA ${ }^{2}$ \\ ${ }^{1}$ Graduate School of Life and Environmental Sciences, University of Tsukuba, 1-1-1 Tennoudai, Tsukuba-shi, \\ Ibaraki 305-8572, Japan \\ ${ }^{2}$ Laboratory of Animal Ecology, Department of Biology, Joetsu University of Education, 1 Yamayashiki-machi, \\ Joetsu-shi, Niigata 943-8512, Japan
}

\section{ORNITHOLOGICAL SCIENCE \\ (C) The Ornithological Society of Japan 2010}

\begin{abstract}
The maintenance of multiple ornaments by animals can be explained when those multiple ornaments are sexually selected. However, there have been only a few studies of sexual selection on multiple ornaments. We investigated sexual selection on two ornaments, plumage coloration and white spots in the tail, in a population of Barn Swallows Hirundo rustica gutturalis in Japan. There was sexual dimorphism in throat coloration and in the size of the white spots in the tail. Males with a less saturated (colourful) throat and larger white spots in the tail bred earlier than others, indicating a mating advantage for these males. These trends are what would be expected if these ornaments were indeed sexually selected.
\end{abstract}

Key words Ornaments, Plumage coloration, Tail length, Throat patch, White spots in the tail
Sexual selection leads to ornamentation of traits that confer an advantage in mate acquisition (Andersson 1994). There have been now many studies of sexual selection on single male ornaments (reviewed in Andersson 1994; Hill \& McGraw 2006). However, males of many species have more than one ornament (Møller \& Pomiankowski 1993). Why do these species have multiple ornaments?

One explanation for multiple ornaments is that some ornaments, for which sexual selection has been lost, are nonetheless maintained because they are not costly (Møller \& Pomiankowski 1993). This explanation, however, cannot be applied to costly ornaments because such ornaments are easily lost through natural selection when the ornaments are no longer sexually selected (Schluter \& Price 1993). Multiple costly ornaments can be explained when the multiple ornaments are sexually selected (Møller \& Pomiankowski 1993). However, there have been only a few studies of sexual selection on multiple ornaments (e.g. the Scarlet-tufted Malachite Sunbird Nectarinia johnstoni: Evans \& Hatchwell 1992a, b; the Yellowbrowed Leaf Warbler Phylloscopus inornatus: Mar-

(Received 3 August 2010; Accepted 18 October 2010)

\# Corresponding author, E-mail: perorobomusadiobe@gmail.com chetti 1998; the Red-collared Widowbird Euplectes ardens: Andersson et al. 2002; the Lark Bunting Calamospiza melanocorys: Chaine \& Lyon 2008).

The Barn Swallow Hirundo rustica is a classic model species for sexual selection, because experimental manipulation has proven the male's long tail to be sexually selected (e.g. Møller 1988; reviewed in Møller 1994). However, it has recently been shown that long tails are also naturally selected because they provide better aerodynamic efficiency and flight manoeuvrability (e.g. Norberg 1994; Buchanan \& Evans 2000; Cuervo \& Ayala 2005), suggesting that sexual selection on this ornament may be less important than previously thought. Only a small proportion of the total length of the tail is sexually selected (Evans 1998; Buchanan \& Evans 2000; Rowe et al. 2001; Bro-Jørgensen et al. 2007). Nevertheless, the Barn Swallow is a useful species for studying sexual selection because it has at least two other sexually selected ornaments: plumage coloration, including its red throat patch (Ninni 2003; Safran \& McGraw 2004; Safran et al. 2005), and white spots in the tail (Kose \& Møller 1999; Kose et al. 1999). These two ornaments are shown to be costly in some populations (throat coloration: probably physiological costs: Ninni 2003; Norris et al. 2009; Safran et al. 2010; 
white spots in the tail: cost of feather breakage and parasites: Kose \& Møller 1999; Kose et al. 1999), and thus seem difficult to maintain without sexual selection. However, since previous studies have focused on only one trait (i.e. the former on throat coloration and the latter on white spots in the tail), it is not known whether or not these two ornaments are sexually selected in a single population.

We studied sexual selection on two ornaments, plumage coloration and white spots in the tail, in male Barn Swallows H. r. gutturalis in Japan. For this purpose, we studied the sexual dimorphism of these ornaments and the relationship between the male ornaments and the laying date of their mates, a recognized index of mating advantage (cf. Andersson 1994; Møller 1994). Throat patch area and coloration are represented as plumage coloration in this study because this subspecies has a large throat patch and whitish ventral plumage (Cramps 1988; Turner 2006). Tail length, which is reported to be sexually selected in European populations of the Barn Swallows (Møller 1994), was also included in the analysis.

\section{METHODS}

\section{1) Study site}

This study was conducted from March to August in 2005 and 2006 in a residential area of Joetsu City, Niigata Prefecture, Japan $\left(37^{\circ} 07^{\prime} \mathrm{N}, 138^{\circ} 15^{\prime} \mathrm{E} ; 10 \mathrm{~m}\right.$ above sea level.). There, Barn Swallows nest under the eaves of a covered sidewalk along the street and breed in a loose colony (see Tajima \& Nakamura 2003). The study site was divided into two areas. One was used to record arrival and laying date and to take measurements of the birds (males: $\mathrm{N}_{2005,2006}=110$, 97; females: $\mathrm{N}_{2005,2006}=120,89$ ). The other was used only to take measurements (males: $\mathrm{N}_{2005,2006}=71,16$; females: $\mathrm{N}_{2005,2006}=69,13$ ) because we conducted a preliminary study for another purpose in this area. We included the latter area in order to provide a large sample size for sexual dimorphism, which enabled us to obtain relatively stable estimates, although qualitatively similar results were obtained when we excluded the latter area.

\section{2) Measurements}

Adult swallows were captured in sweep nets while roosting at night, mainly soon after clutch completion. Birds were provided with a standard, numbered aluminium ring and an individually recognisable combination of two or three half-sized coloured rings made from plastic rings (AC Hughes, Middlesex). The sex of an individual was determined by the presence (female) or absence (male) of an incubation patch. In 2006, adults were categorized into two classes on the basis of ringing records: (i) birds known to be $\geq 2$ years old (i.e. birds that were known to have bred in previous seasons) and (ii) birds of unknown age. Nest ownership was subsequently determined with binoculars. At capture, we measured tarsus length, body weight, tail length, the sizes of the white spots in the tail, and the throat patch area, and collected several throat feathers. Tail length was defined as the length of the right outermost tail feather to the nearest $0.01 \mathrm{~mm}$. When analyzing laying date, we omitted from our samples all birds with broken or missing outermost tails $\left(\mathrm{N}_{2005,2006}=9,12\right)$. The size of the white spots in the tail was defined as the sum of the lengths of the white spots of the two outermost right tail feathers. This method differs from those of previous studies (Kose \& Møller 1999; Kose et al. 1999) and was chosen to minimize the handling time of the birds.

Throat patch area was defined as the area of the swallow's red throat patch; this was measured by placing a transparent plastic sheet over the throat region, ensuring that the feathers were lying flat in their natural position, and tracing the edges of the patch on to the sheet with a marker pen (cf. Lendvai et al. 2004). We scanned the sheet and measured the area of the patch $\left(\mathrm{mm}^{2}\right)$ using Scion Image software (Scion Corporation, Frederick, MD). Each bird's throat patch was traced twice, and the mean of the two measurements was used. The repeatability of the measurements was high (males: $\mathrm{N}_{2005,2006}=147,112$, repeatability ${ }_{2005,2006}=0.87,0.87, \mathrm{~F}>14.13, \mathrm{P}<0.0001$; females: $\mathrm{N}_{2005,2006}=166,100$, repeatability ${ }_{2005,2006}=0.80$, $0.85, \mathrm{~F}>8.84, \mathrm{P}<0.0001$; Lessells \& Boag 1987).

Once in the laboratory, we placed five throat feathers, which had been collected at capture, on a piece of white paper so that the edges of the feathers were on contact. The feather samples were scanned at 800 dpi resolution using a scanner (GT 9300 UF; Epson, Tokyo, Japan), and the images obtained were imported into Photoshop Elements 3.0 (Adobe Systems, San Jose, CA). We measured the mean red-greenblue $(\mathrm{RGB})$ values for a $30 \times 30$ pixel square near the distal end of the feather sample. The mean RGB values were converted into hue-saturation-brightness (HSB) values, using the algorithm described by Foley and van Dam (1984). The repeatability of these variables was highly significant when birds with two 
feather samples were used $(0.65 \leq$ repeatability $\leq 0.91, \mathrm{~N}>30, \mathrm{~F}>4.69, \mathrm{P}<0.001$; see Hasegawa et al. 2008). Details of the methodology are described elsewhere (Hasegawa et al. 2008).

Since the hue and brightness of throat coloration fades linearly with time, we corrected throat coloration using the field correction methods described by Hasegawa et al. (2008): corrected (H, S, $\mathrm{B})=$ measured $(\mathrm{H}, \mathrm{S}, \mathrm{B})-(0.023,0,0.097) \times$ days elapsed from the date of capture of the first bird to the date of capture of each bird. Each colour variable positively correlated with the others even after correction for seasonal colour fading (sex and year separately: H-S: $0.33<r<0.81, \mathrm{P}<0.0001$; S-B: $0.44<r<$ $0.80, \mathrm{P}<0.0001$; B-H: $0.81<r<0.94, \mathrm{P}<0.0001)$. Thus, saturation value was considered to be representative of plumage coloration, because this variable does not need to be corrected for plumage colour fading (Hasegawa et al. 2008). Positive correlations between colour variables, imply that throat plumage with a lower saturation value is generally redder (i.e. lower hue value) and darker (i.e. lower brightness value). Although Ninni (2003) and Safran and McGraw (2004) reported different relationships among colour variables (in particular, saturation was negatively correlated with other variables), it is not clear whether these differences result from populationbased or method-based differences, or other reasons.

\section{3) Observation}

We recorded the time of arrival of each marked bird every day and inspected nests every other day to record the laying date, which was defined as the date of laying of the first egg of the first clutch. Since we failed to capture some nesting birds during their first clutch, we were unable to distinguish between renesting or the second clutch of such birds, from the first clutch of late breeding birds. Since the inclusion of these birds tended to obscure the patterns of ornaments and laying date (cf. Hill et al. 1999), our test of male ornaments and laying date was conservative. We captured ca. $70 \%$ of the nesting birds from both areas at the end of both seasons.

\section{4) Statistical procedures}

We compared the sex differences in morphology using Welch's t-test (cf. Møller 1994). To investigate the correlation among male traits, Pearson's productmoment correlation was used. We used a linear mixed-effect model (LME, 'Imer' in $\mathrm{R}$ package 'Ime4') to examine the relationships between male ornaments and laying date. This LME framework was applied to account for the repeated usage of individuals in both the study years, by including the identity of the individuals as a random effect. The significances of the terms in the LME frameworks were based on the difference in deviance and degrees of freedom of the models with and without the predictor in question $\left(\chi^{2}\right.$-test). We statistically controlled for the effects of body condition of males and study year as additional predictors in the LME. In accordance with a previous study (Kojima et al. 2009), body condition was defined as a residual from a regression of body mass against tarsus length (General linear model: $\mathrm{N}=288$; tarsus: coefficient $=0.51, \mathrm{t}=3.77$, $\mathrm{P}<0.001$; years: coefficient $=-0.51, \quad \mathrm{t}=-4.24$, $\mathrm{P}<0.0001$; intercept: coefficient $=12.14, \mathrm{t}=8.33$, $\mathrm{P}<0.0001$ ).

To control for the effects of any age difference among males, in their ornaments and laying dates (Møller \& de Lope 1999), which might confound the relationship, analyses were also conducted using a general linear model using only males known to be $\geq 2$ years old in 2006 . We did not adopt an alternative method using two male categories (i.e. males known to be $\geq 2$ year old versus males of unknown age) as a fixed factor in a general linear model using all males captured in 2006. This was because the category 'age-unknown' males also included some un-ringed males that were $\geq 2$ years old, which might confound the relationship between male ornaments and laying date. The significance of the terms in the general linear model frameworks was based on the difference in deviance and degrees of freedom of the models with and without the predictor in question (F-test). For general linear model analysis using males known to be $\geq 2$ years old, we added body condition and arrival date as additional predictors. Since pairs that reunite in subsequent years breed earlier than others (Saino et al. 2002), we excluded four males that had reunited with their mates of the previous year. However, inclusion of these males did not affect the results.

We first fitted a full model containing all explanatory variables. In the case of the LME analysis, we also included the interactions between male morphologies and study year in a full model because the relationship between each ornament and laying date might differ between study years. A final model was selected by progressively eliminating non-significant interaction terms $(\mathrm{P}>0.1)$ and then non-significant main terms. Collinearity between variables can cause problems in multiple regressions, but this is generally 
not considered problematic when $|r|<0.70$, as in the present study (cf. Møller 2004). In the tables, the statistics and $\mathrm{P}$ values of significant terms $(\mathrm{P}<0.05)$ are from the final model (all significant terms included), whereas statistics and P-values of non-significant terms are from the final model and each nonsignificant term added separately (cf. Owens et al. 1995). When there were influential points or outliers that substantially affected the results, we present the results both including and excluding the data points (Grafen \& Hails 2002). The total sample size in the LME and general liner model analyses was 125 $\left(\mathrm{N}_{\text {group }}=111 ; \mathrm{N}_{2005,2006}=68,57\right)$ and 22 , respectively (14 males in 2005 and 13 males in 2006 could not be used because some measurements were missing for them or because difficulties were incurred during their capture). The mean values of all statistical measurements are reported with \pm 1 SE. All data analyses were performed using the $\mathrm{R}$ (version 2.8.0) statistical package ( $\mathrm{R}$ Development Core Team 2008).

\section{RESULTS}

\section{1) Sex differences and inter-correlation between ornaments}

In both study years, males had less saturated throat coloration than females (Table 1). Similar results were obtained among birds known to be $\geq 2$ years old (Table 1). Males tended to have larger throat patches (significantly larger in 2005, but not in 2006 or in birds known to be $\geq 2$ years old; see Table 1).

Males had longer tails and larger white spots in the tail than females (Table 1). This was also the case after excluding birds of unknown age (Table 1).

Male tail length correlated positively with the size of the white spots in the tail (2005: $r=0.22, \mathrm{~N}=164$, $\mathrm{P}<0.01 ; 2006: r=0.31, \mathrm{~N}=112, \mathrm{P}<0.001)$ and negatively with the saturation value of throat plumage (i.e. males with longer tails also had colourful throats: 2005: $r=-0.27, \mathrm{~N}=121, \mathrm{P}<0.01 ; 2006: r=-0.29$, $\mathrm{N}=107, \mathrm{P}<0.01)$ in 2005 and 2006. Similar results were obtained for birds known to be $\geq 2$ years old (tail length vs. the size of the white spots: $r=0.46$, $\mathrm{N}=47, \mathrm{P}<0.01$; tail length vs. saturation value: $r=-0.28, \mathrm{~N}=44, \mathrm{P}=0.07)$. There were no other significant relationships among the male ornaments (all: $\mathrm{P}>0.05$ ).

Male body condition correlated positively with tail length (2005: $r=0.22, \quad \mathrm{~N}=163, \mathrm{P}<0.01 ; 2006$ : $r=0.25, \mathrm{~N}=111, \mathrm{P}<0.01)$ and negatively with the saturation value of throat plumage (2005: $r=-0.24$, $\mathrm{N}=132, \quad \mathrm{P}<0.001 ; \quad 2006: \quad r=-0.33, \quad \mathrm{~N}=106$, $\mathrm{P}<0.001$ ). On the other hand, there were no significant relationships between male body condition and the saturation value of throat plumage $(\mathrm{N}=44$, $r=-0.19, \mathrm{P}=0.22)$ and other ornaments in males known to be $\geq 2$ years old $(\mathrm{N}=47,|r|<0.14$, $\mathrm{P}>0.33)$.

Table 1. Sexual dimorphism in Hirundo rustica gutturalis.

\begin{tabular}{|c|c|c|c|c|}
\hline & & Males & & Females \\
\hline \multicolumn{5}{|l|}{ Red throat patch } \\
\hline \multirow{3}{*}{$\begin{array}{l}\text { Saturation } \\
\quad(\text { least saturated }=0, \\
\text { most saturated }=255)\end{array}$} & 2005 & $118.49 \pm 0.39(133)$ & $* *$ & $121.88 \pm 0.30(152)$ \\
\hline & 2006 & $109.20 \pm 0.59(107)$ & $* *$ & $114.29 \pm 0.52(95)$ \\
\hline & $\geq 2$ years old ${ }^{1}$ & $107.11 \pm 0.79(44)$ & $* *$ & $112.37 \pm 0.89(31)$ \\
\hline \multirow[t]{3}{*}{ Patch area $\left(\mathrm{mm}^{2}\right)$} & 2005 & $514.88 \pm 5.79(147)$ & $* *$ & $493.25 \pm 4.80(166)$ \\
\hline & 2006 & $511.96 \pm 7.65(112)$ & & $500.04 \pm 6.59(100)$ \\
\hline & $\geq 2$ years old ${ }^{1}$ & $517.26 \pm 11.14$ & & $499.24 \pm 12.30$ \\
\hline \multicolumn{5}{|l|}{ Tail ornaments } \\
\hline \multirow[t]{3}{*}{ Tail length (mm) } & 2005 & $94.42 \pm 0.64(164)$ & $* *$ & $79.93 \pm 0.34(179)$ \\
\hline & 2006 & $93.89 \pm 0.76(112)$ & $* *$ & $80.23 \pm 0.49(99)$ \\
\hline & $\geq 2$ years old ${ }^{1}$ & $96.93 \pm 1.28(47)$ & $* *$ & $82.42 \pm 0.84(31)$ \\
\hline \multirow[t]{3}{*}{ White spots' size (mm) } & 2005 & $39.00 \pm 0.41(178)$ & $* *$ & $29.39 \pm 0.39(184)$ \\
\hline & 2006 & $37.07 \pm 0.52(112)$ & $* *$ & $28.64 \pm 0.55(101)$ \\
\hline & $\geq 2$ years old ${ }^{1}$ & $38.19 \pm 0.85(47)$ & $* *$ & $28.42 \pm 0.94(32)$ \\
\hline
\end{tabular}

Values represented as mean $\pm \mathrm{SE}$; sample size in parentheses.

Differences between the sexes were tested with the t-test; $* \mathrm{P}<0.05$, ** $\mathrm{P}<0.01$.

$1 \geq 2$ years old included only birds known to be $\geq 2$ years old from the ringing records. 
Table 2. Results of LME analysis predicting variation in laying date using all males.

\begin{tabular}{cc}
\hline & $2005+2006(\mathrm{~N}=125)$ \\
\hline Red throat patch & \\
Saturation & $0.47(<0.01)$ \\
Patch size & \\
Tail ornaments & $-2.46(0.01)$ \\
Tail length & $-2.29(0.03)$ \\
White spots size & $0.73(0.47)$ \\
Other & \\
Body condition &
\end{tabular}

Estimates of each coefficient and $\mathrm{P}$ values for $\chi^{2}$-test are shown. The year and its interaction with the main variables are not shown because all the relationships were non-significant $(\mathrm{P}>0.1)$.

${ }^{\dagger}$ indicates the variables retained in the final models by stepdown model selection procedures.

\section{2) Laying date}

The median laying date of the first egg of the first clutch was 8 May (range=17 April-17 June) in 2005, and 9 May (range $=21$ April-13 June) in 2006. Males known to be $\geq 2$ years old started breeding significantly earlier than males of unknown age (males known to be $\geq 2$ years old: median date $=2$ May, range $=21$ April-13 May, $\mathrm{N}=27$; age-unknown males: median date $=16$ May, range $=25$ April -13 June, $\mathrm{N}=33 ; \mathrm{t}=5.59, \mathrm{P}<0.0001)$. The laying dates of males known to be $\geq 2$ years old were less variable than males of unknown age (Levene's test; $\mathrm{F}=10.28$, $\mathrm{P}=0.002$ ).

The laying date was predicted by three male ornaments: the saturation value of throat plumage, tail length, and the size of the white spots in the tail (Table 2). Males with lower saturation values, longer tails, and larger white spots in the tail bred earlier than other males. These three ornaments also predicted the laying date in males known to be $\geq 2$ years old (Table 3 left; Fig. 1). It should be noted that the sign of the coefficient of tail length was reversed in males known to be $\geq 2$ years old as compared with in the LME analysis using all males. The positive relationship between tail length and the laying date was caused by an outlier (i.e. one male with a particularly long tail, whose tail was more than 2.44 SD longer than the average tail length), because the significant positive relationship between tail length and laying date disappeared when we repeated the analysis after omitting the longest-tailed male (Table 3 right).
Table 3. Results of general linear model analyses predicting variation in laying date among males known to be $\geq 2$ years old.

\begin{tabular}{ccc}
\hline & $\begin{array}{c}\text { All data } \\
(\mathrm{N}=22)\end{array}$ & $\begin{array}{c}\text { Excluding an outlier }{ }^{1} \\
(\mathrm{~N}=21)\end{array}$ \\
\hline $\begin{array}{c}\text { Red throat patch } \\
\text { Saturation }\end{array}$ & $+3.36(0.01)$ & $+3.17(0.01)$ \\
Patch size & $-0.97(0.42)$ & $-0.67(0.58)$ \\
Tail ornaments & & \\
Tail length & $\dagger 3.36(0.02)$ & $1.83(0.16)$ \\
White spots size & $-4.82(<0.01)$ & $-3.67(<0.01)$ \\
Other & & $0.20(0.87)$ \\
Arrival date & $-0.62(0.61)$ & $0.71(0.56)$ \\
Body condition & $0.63(0.64)$ & \\
\hline
\end{tabular}

Each column represents the results of the general linear model analyses: estimates of each coefficient and $\mathrm{P}$ values for F-tests. ${ }^{1}$ The analysis after omitting the longest-tailed male, whose tail length was more than 2.44 SD longer than the average tail length.

$\dagger$ indicates the variables retained in the final models by stepdown model selection procedures.

\section{DISCUSSION}

Our results suggest that throat coloration and white spots in the tail are sexually selected in our study population of the Barn Swallow. First, there was sexual dimorphism in throat coloration and the size of the white spots in the tail (Table 1). Second, males with a less saturated throat and larger white spots in the tail bred earlier than others, even after controlling for the effects of male age and body condition (Table $2 \&$ Fig. 1), indicating that such males experience a mating advantage. These males should experience high reproductive success because the number of fledglings and the probability of recruitment of young increases among Barn Swallows that breed earlier in the breeding season (e.g. Grüebler \& Naef-Daenzer 2010; reviewed in Møller 1994; Turner 2006). These trends are what would be expected if these ornaments were indeed sexually selected.

These two ornaments, white spots in the tail and plumage coloration, have already been shown to be related to laying date in some populations and it is suggested that they are sexually selected in each population (white spots in the tail: Kose \& Møller 1999; Kose et al. 1999; plumage coloration: Safran \& McGraw 2004). However, to explain the maintenance of these two ornaments, which have been shown to be costly at least in some populations (throat coloration: 

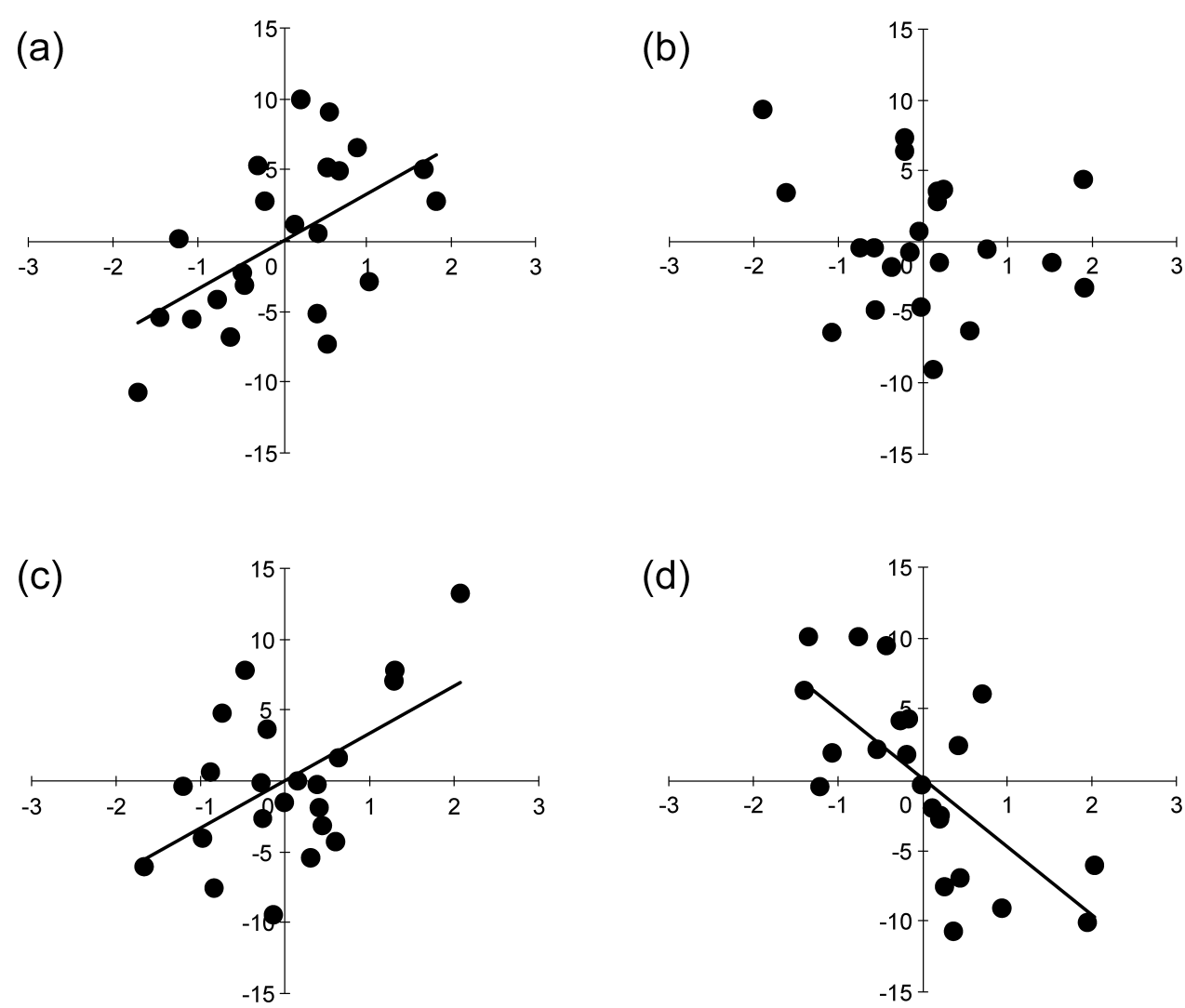

Fig. 1. Relationships between male ornaments (x-axis) and the date of breeding onset (y-axis), controlling for other ornaments in male Barn Swallows known to be $\geq 2$ years old and excluding mate re-united birds: (a) throat coloration (saturation), (b) throat patch area, (c) tail length, and (d) the size of the white spots in the tail. Both axes show the residuals controlling for the terms retained in the final model using males known to be $\geq 2$ years old (Table 3 left). Linear regression lines are shown.

Ninni 2003; Norris et al. 2009; Safran et al. 2010; white spots in the tail: Kose \& Møller 1999; Kose et al. 1999), the two ornaments need to be sexually selected in a single population. Otherwise, the maintenance of the two ornaments is not possible or requires another mechanism to explain them (e.g. sufficient gene flow across populations with different sexual selection; reviewed in Bro-Jørgensen 2010). This is the first study to show a relationship between laying date and the two ornaments in a single population of Barn Swallows, suggesting sexual selection on the two male ornaments. As has been shown in other species (e.g. Evans \& Hatchwell 1992a, b; Marchetti 1998; Andersson et al. 2002; Caine \& Lyon 2008), multiple ornaments in the Barn Swallow can also be explained by sexual selection on the ornaments.

In the current study, male body condition was not found to be related to his mate's laying date, suggesting that body condition is less important than throat coloration and white spots in the tail at least in determining the timing of breeding of males. Our results are, at first glance, inconsistent with a previous study (Kojima et al. 2009), which suggests that sexual selection favors males that are in good body condition. However, our study differed from theirs in many points (e.g. they used paternity as a response variables, measured body condition soon after arriving, and studied a different population). Thus, we could not refer the causation of the difference between their study and ours.

Of the two remaining candidate targets of sexual selection, tail length was not found to be negatively related to laying date after controlling for the effects of male age (Table 3 \& Fig. 1). This is consistent with previous studies that found no sexual selection for long tails in some other populations of Barn Swallows (Safran \& McGraw 2004; Neuman et al. 2007; but see Kleven et al. 2006), including a Japanese population (Kojima et al. 2009). Tail length is perhaps, therefore, less important in sexual selection in our population, at least for determining laying date than throat coloration and white spots in the tail. In addi- 
tion, the other candidate, throat patch area, showed only small sexual dimorphism (Table 1) and no relationship with laying date (Table 2), suggesting that this trait is less important for breeding early.

Here, we have shown that two male ornaments, throat coloration and white spots in the tail, confer mating advantage in terms of early breeding in a population of Barn Swallows in Japan. Since the two ornaments are related to laying date, sexual selection can explain the maintenance of these two ornaments. However, the current study did not elucidate the mechanism of selection. Since both female mate choice and male-male competition can predict the early breeding of well-ornamented males (Wiley \& Poston 1996), further studies (e.g. manipulation experiments) are necessary to show how inter- and intra-sexual selection can maintain multiple ornaments simultaneously.

\section{ACKNOWLEDGMENTS}

We are grateful to the residents of Joetsu City for their kind support and assistance. We thank A. P. Møller for useful information. This manuscript benefited from comments by R. J. Safran. We also thank the members of the Laboratory of Animal Ecology of Joetsu University of Education and the Laboratory of Conservation Ecology of University of Tsukuba. We also thank Takahiro Morosawa for his advice on statistical analyses.

\section{REFERENCES}

Andersson M (1994) Sexual Selection. Princeton University Press, Princeton.

Andersson S, Pryke SR, Örnborg J, Lawes MJ \& Andersson M (2002) Multiple receivers, multiple ornaments, and a trade-off between agonistic and epigamic signaling in a widowbird. Am Nat 160: 683-691.

Bro-Jørgensen J (2010) Dynamics of multiple signaling systems: animal communication in a world in flux. Trends Ecol Evol 25: 292-300.

Bro-Jørgensen J, Johnstone RA \& Evans MR (2007) Uninformative exaggeration of male sexual ornaments in barn swallows. Curr Biol 17: 850-855.

Buchanan KL \& Evans MR (2000) The effect of tail streamer length on aerodynamic performance in the barn swallow. Behav Ecol 11: 228-238.

Chaine AS \& Lyon BE (2008) Adaptive plasticity in female mate choice dampens sexual selection on male ornaments in the lark bunting. Science 319: 459-462.

Cramp S (1988) The Birds of the Western Palearctic, Vol 5. Oxford University Press, Oxford.
Cuervo JJ \& Ayala RM (2005) Experimental tail shortening in Barn Swallows (Hirundo rustica) affects haematocrit. Funct Ecol 9: 828-835.

Dor R, Safran RJ, Sheldon FH, Winkler DQ \& Lovette IJ (2010) Phylogeny of the genus Hirundo and the Barn Swallow subspecies complex. Mol Phyl Evol 56: 409-418.

Evans MR (1998) Selection on swallow tail streamers. Nature 394: 233-234.

Evans MR \& Hachwell BJ (1992a) An experimental study of male adornment in the scarlet-tufted malachite sunbird. I. The role of pectoral tufts in territorial defence. Behav Ecol Sociobiol 29: 413-419.

Evans MR \& Hachwell BJ (1992b) An experimental study of male adornment in the scarlet-tufted malachite sunbird. II. The role of the elongated tail in mate choice and experimental evidence for a handicap. Behav Ecol Sociobiol 29: 421-427.

Foley JD \& van Dam A (1984) Intensity and color. In: Fundamentals of Interactive Computer Graphics. 593-622. Addison-Wesley, Philippines.

Grafen A \& Hails R (2002) Modern Statistics for the Life Sciences. Oxford University Press, Oxford.

Grüebler MU \& Naef-Daenzer B (2010) Fitness consequences of timing of breeding in birds: data effects in the course of a reproductive episode. J Avian Biol 41: 282-291.

Hasegawa M, Arai E, Watanabe M \& Nakamura M (2008) Methods for correcting plumage color fading in the Barn Swallow. Ornithol Sci 7: 117-122.

Hill GE \& McGraw KJ (2006) Bird coloration. II. Function and evolution. Harvard Univ. Press, Cambridge.

Hill GE, Nolan PM \& Stoehr AM (1999) Pairing success relative to male plumage redness and pigment symmetry in the house finch: temporal and geographic constancy. Behav Ecol 10: 48-53.

Kleven O, Jacobsen F, Izadnegahdar R, Robertson RJ \& Lifjeld JT (2006) Male tail streamer length predicts fertilization success in the North American barn swallow (Hirundo rustica erythrogaster). Behav Ecol Sociobiol 59: 412-418.

Kojima W, Kitamura W, Kitajima S, Ito Y, Ueda K, Fujita G \& Higuchi H (2009) Female barn swallows gain indirect but not direct benefits through social mate choice. Ethology 115: 939-947.

Kose M \& Møller AP (1999) Sexual selection, feather breakage and parasites: the importance of white spots in the tail of the barn swallow. Behav Ecol Sociobiol 45: 430-436.

Kose M, Mänd R \& Møller AP (1999) Sexual selection for white tail spots in the barn swallow in relation to habitat choice by feather lice. Anim Behav 58: 1201-1205. 


\section{HASEGAWA et al.}

Lendvai AZ, Kis J, Szekely T \& Cuthill IC (2004) An investigation of mate choice based on manipulation of multiple ornaments in Kentish plovers. Anim Behav 67: 703-709.

Lessells CM \& Boag PT (1987) Unrepeatable repeatabilities: a common mistake. Auk 104: 116-121.

Marchetti K (1998) The evolution of multiple male traits in the yellow-browed leaf warbler. Anim Behav 55: 361-376.

Møller AP (1988) Female choice selects for male sexual tail ornaments in the monogamous swallow. Nature 332: 640-642.

Møller AP (1994) Sexual Selection and the Barn Swallow. Oxford University Press, Oxford.

Møller AP (2004) Rapid temporal change in frequency of infanticide in a passerine bird associated with change in population density and body condition. Behav Ecol 15: 462-468.

Møller AP \& de Lope F (1999) Senescence in a shortlived migratory bird: age-dependent morphology, migration, reproduction and parasitism. J Anim Ecol 68: 163-171.

Møller AP \& Pomiankowski A (1993) Why have birds got multiple sexual ornaments? Behav Ecol Sociobiol 32: $167-176$.

Neuman CR, Safran RJ \& Lovette IJ (2007) Male tail streamer length does not predict apparent or genetic reproductive success in North American barn swallows Hirundo rustica erythrogaster. J Avian Biol 38: 28-36.

Ninni P (2003) Carotenoid signals in Barn Swallows. $\mathrm{PhD}$ thesis, Université Pierre et Marie Curie, Paris, France.

Norberg RA (1994) Swallow tail streamer is a mechanical device for self deflection of tail leading edge, enhancing aerodynamic efficiency and flight manoeuvrability. Proc R Soc Lond B 257: 227-233.

Norris DR, Kleven O, Johnsen A \& Kyser TK (2009) Melanin-based feather colour and moulting latitude in a migratory songbird. Ethology 115: 1009-1014.
Owens IPF, Dixon A, Burke T \& Thompson DBA (1995) Strategic paternity assurance in the sex-role reversed Eurasian dotterel (Charadrius morinellus): behavioral and genetic evidence. Behav Ecol 6: 14-21.

R Development Core Team (2008) R: A language and environment for statistical computing. $\mathrm{R}$ Foundation for Statistical Computing, Vienna, Austria. ISBN 3900051-07-0, URL http://www.R-project.org.

Rowe LV, Evans MR \& Buchanan KL (2001) The function and evolution of the tail streamer in hirundines. Behav Ecol 12: 157-163.

Safran RJ \& McGraw KJ (2004) Plumage coloration, not length or symmetry of tail-streamers, is a sexually selected trait in North American barn swallows. Behav Ecol 15: 455-461.

Safran RJ, Neuman CR, McGraw KJ \& Lovette IJ (2005) Dynamic paternity allocation as a function of male plumage color in barn swallows. Science 309: 2210-2212.

Safran RJ, McGraw KJ, Wilkins MR, Hubbard JH \& Marling J (2010) Positive Carotenoid Balance Correlates with Greater Reproductive Performance in a Wild Bird. PloS One 5: e9420. doi: 10.1371/journal. pone.0009420.

Saino N, Ambrosini R, Martinelli R \& Møller AP (2002) Mate fidelity, senescence in breeding performance and reproductive trade-offs in the barn swallow. J Anim Ecol 71: 309-319.

Schluter D \& Price T (1993) Honesty, perception and population divergence in sexually selected traits. Proc R Soc Lond B 253: 117-122.

Tajima K \& Nakamura M (2003) Response to manipulation of partner contribution: a handicapping experiment in the Barn Swallow. Ornithol Sci 2: 65-72.

Turner AK (2006) The Barn Swallow. T \& A D Poyser, London.

Wiley RH \& Poston J (1996) Indirect mate choice, competition for mates, and coevolution of the sexes. Evolution 50: 1371-1381. 